Open Access

\title{
Macro- and microscopic findings of ICG fluorescence in liver tumors
}

\author{
Shingo Shimada ${ }^{*}$, Seiji Ohtsubo², Kazuhiro Ogasawara ${ }^{1}$ and Mitsuo Kusano ${ }^{3}$
}

\begin{abstract}
Background: Reports detailing microscopic observations of indocyanine green (ICG) fluorescence imaging (IFI) in hepatocellular carcinoma (HCC) and metastatic liver cancer are rare. We were able to perform macro- and microscopic IFI results in postoperative paraffin-embedded tissue samples and formalin-fixed specimens from liver tumors.

Methods: Between April 2010 and March 2014, 19 patients with HCC or liver metastases of colorectal tumors underwent liver resection. ICG solution was injected into the peripheral vein from 14 to 2 days prior to operation. We observed liver tumor IFI during the laparotomy and IFI in resected liver sections using a photo dynamic emission (PDE) camera. The IFI of paraffin-embedded tissue samples was observed using a charge-coupled device (CCD) camera. Moreover, we microscopically performed tissue section IFI using a fluorescence microscope with an ICG-B-NQF.

Results: We performed that IFI characteristics depended on tumor type macroscopically and microscopically. In normal liver tissue, fluorescence consistent with the bile canaliculus was observed. HCC had heterogeneous IFI, forming a total or partial tumor and rim pattern. In metastatic carcinoma, we performed that non-tumor cells in the marginal region showed fluorescence and tumor cells in the central region did not fluoresce.

Conclusions: We confirmed that the variations of ICG fluorescence imaging patterns reflect different tumor characteristics in not only macroscopic imaging as previous reports but also microscopic imaging. Moreover, the ICG fluorescence method is useful for postoperative pathological detection of microscopic lesions in histopathological specimens. ICG fluorescence in paraffin-embedded tissue samples and formalin-fixed specimens is preserved in the long term.
\end{abstract}

Keywords: Indocyanine green, Fluorescence imaging, Liver cancer, Paraffin-embedded tissue, Microscopic findings

\section{Background}

Indocyanine green (ICG) combines with serum proteins in vivo and produces a fluorescence signal [1]. ICG fluorescence imaging (IFI) is increasingly being used in fluorescence-guided surgery, i.e., in breast [2], gastric [3, 4], and esophageal cancer [5] surgeries and vascular surgery [6]. Applications of IFI, including tattooing of liver segments $[7,8]$ and providing biliary tract contrast [9], have been reported in the liver surgery field. Some institutions have recently reported IFI macroscopic features in hepatocellular carcinoma ( $\mathrm{HCC}$ ) and metastatic liver tumors [10-13]. Liver tumors can be observed using fluorescence imaging and generally have heterogeneous

\footnotetext{
* Correspondence: shingoshimada1979@true.ocn.ne.jp

'Department of Surgery, Japan Labor Health and Welfare Organization, Kushiro Rosai Hospital, 13-12, Nakazono-cho, Kushiro, Hokkaido 085-8533, Japan

Full list of author information is available at the end of the article
}

fluorescence in the central region of the $\operatorname{HCC}[10,11]$. In contrast, metastatic liver tumors have a corona-like fluorescence pattern in the marginal region of the tumor [10, 12, 13]. Generally, IFI can be used for intraoperative tumor detection. However, there are few reports focused on postoperative IFI samples. Particularly, reports detailing microscopic IFI observations in HCC and metastatic liver tumors are rare.

In this study, we performed macro- and microscopic IFI characteristics in liver tumors using postoperative paraffin-embedded tissue and formalin-fixed specimens.

\section{Methods}

Between April 2010 and March 2014, 19 patients with liver tumors underwent liver resection at the Japan Labor Health and Welfare Organization, Kushiro Rosai Hospital, Department of Surgery in Kushiro, Japan. This 
study was approved by the Ethics Committee of the Kushiro Rosai Hospital and performed according to the Helsinki Declaration guidelines. The clinicopathological characteristics and surgical data of the patients are shown in Table 1.

ICG solution was injected into the peripheral vein from 14 to 2 days prior to the operation.

To evaluate the liver tissue, we also performed intraoperative ICG injection in several cases.

The ICG injection dose was $0.5 \mathrm{mg} / \mathrm{kg}$. We observed the liver tumor IFI during the laparotomy and IFI in resected liver sections using a photo dynamic emission (PDE) camera (Hamamatsu Photonics, Hamamatsu). The IFI of paraffin-embedded tissue was obtained using a charge-coupled device (CCD) camera with a lightemitting diode at a 760-nm wavelength as the light emitter and a cut filter to filter light at wavelengths below $820 \mathrm{~nm}$ as the detector. Moreover, we microscopically observed tissue section IFI using a fluorescence microscope with an ICG-B-NQF (OPTO-LINE, Tokyo).

\section{Results}

\section{Clinicopathological characteristics}

A total of 19 patients were observed in this study. Of these patients, 12 patients had hepatocellular carcinoma, while seven patients had liver metastases of colorectal cancer (CRC). In HCC patients, the numbers of males and females were eight and four, respectively. Two cases were well differentiated, four cases had moderate differentiation and five cases had poor differentiation. One case had unknown differentiation. Four cases had partial resections performed, five cases had liver subsegmentectomies performed, two cases had liver segmentectomies performed, and one case had a hepatic lobectomy performed. Two cases had normal livers (NL), one case had chronic hepatitis $(\mathrm{CH})$, four cases had liver fibrosis (LF), and five cases had liver cirrhosis (LC). In case No. 10, we were able to detect and resect by using IFI the main tumor and also small metastases, which were not identified with the preoperative imaging. In metastatic liver tumor cases, all patients were male and had partial resections performed. All cases had no cirrhosis or fibrosis (Table 1).

\section{Intraoperative observation}

We were able to detect the targeted tumor by using IFI in all cases (Table 1). In the majority of cases, we were able to observe the whole tumor fluorescence (Fig. 1a), except in three cases with metastatic tumors derived from CRC that had rim fluorescence (Fig. 1b). Normal livers (noncancerous sections) had uniform fluorescence after intraoperative ICG injection (Fig. 1c) while cirrhotic livers (non-cancerous sections) had heterogeneous fluorescence where the regenerated nodule strongly fluoresced (Fig. 1d). After ICG injection, we observed immediate emission and early washout in the normal liver. Conversely, we observed late emission and late washout in the cirrhotic liver as an aggravation of cirrhosis.

\section{Postoperative observation of liver sections}

Six HCC cases had total tumor fluorescence emission (total tumor type), four cases had partial tumor fluorescence emission (partial tumor type), and two cases had rim-like fluorescence (rim type) in the liver sections (Table 1). All cases of well- or moderately differentiated tumors had total tumor type fluorescence (Fig. 2a). In five cases with poorly differentiated HCC, there were no tumors with total tumor type fluorescence, four cases with partial tumor type fluorescence (Fig. 2b), and one case (case 9) with rim type fluorescence (Fig. 2c). Case 12, which had an unknown HCC differentiation classification, had rim type fluorescence (Fig. 2d).

In cases of metastatic liver tumors derived from CRC, all cases had rim-like fluorescence at the marginal region of the tumor in the liver sections (Table 1) (Fig. 2e).

\section{Observations in paraffin-embedded tissue}

ICG fluorescence was not limited to fresh tissues but was also observable in paraffin sections (Fig. 3a-e). In the paraffin-embedded tissue samples, almost all cases had the same results as the sections; however, cases 7, 8, and 11 had different results compared with the liver sections. These samples had the rim type of IFI (Table 2).

We were able to observe tumor fluorescence in samples that were obtained 3 years and 8 months earlier in the paraffin-embedded tissue samples.

\section{Microscopic findings}

Hepatocytes from cirrhotic livers had stronger IFI values than those from non-cirrhotic livers. While hepatocyte IFI values in non-cirrhotic livers were weaker than cirrhotic livers, the IFI values in the bile canaliculus in non-cirrhotic livers were higher than those in cirrhotic livers (Fig. 4a, b).

In hepatocellular carcinoma cases, tumor cells had heterogeneous fluorescence. Total or partial HCC tumor type paraffin-embedded tissue samples had cytoplasmic fluorescence as observed by ICG fluorescence microscopy (Fig. 4c, d). Furthermore, some HCC cases that had rim IFI had nuclear IFI in cancer cells and cytoplasmic IFI in the surrounding non-cancer cells (Fig. 4e, f). Metastatic cancers that had the rim type had cytoplasmic ICG fluorescence in non-cancer cells surrounding cancer cells (Table 2) (Fig. 4g).

\section{Discussion}

In this study, we were able to perform the macroscopic and microscopic characteristics of different tumor types by using ICG fluorescence imaging (IFI). In normal hepatocytes, fluorescence consistent with the bile canaliculus 
Table 1 Clinicopathological characteristics and macroscopic observations of IFI

\begin{tabular}{|c|c|c|c|c|c|c|c|c|c|c|c|c|c|c|c|c|c|c|c|}
\hline Case & Age & Sex & Diagnosis & Location & Size (cm) & Number & $\begin{array}{l}\text { ICGR15 } \\
\text { (\%) }\end{array}$ & AFP & PIVKA-II & CEA & CA19-9 & Operation & $\begin{array}{l}\text { Pathology and } \\
\text { differentiation }\end{array}$ & $v p$ & vv & im & $\begin{array}{l}\text { Non- } \\
\text { cancerous } \\
\text { liver }\end{array}$ & $\begin{array}{l}\mathrm{IFI} \text { of } \\
\text { surface }\end{array}$ & IFI of section \\
\hline 1 & 66 & $\mathrm{~F}$ & $\mathrm{HCC}$ & S6 & $3 \times 3$ & 1 & 11.0 & 2.2 & 16 & NA & NA & Subsegmentectomy & $\begin{array}{l}\text { Hepatocellular } \\
\text { carcinoma-well }\end{array}$ & 0 & 0 & 0 & LC & $\begin{array}{l}\text { Total } \\
\text { tumor }\end{array}$ & $\begin{array}{l}\text { Total, } \\
\text { heterogeneously }\end{array}$ \\
\hline 2 & 79 & $\mathrm{~F}$ & $\mathrm{HCC}$ & S8 & $2 \times 2$ & 1 & 18.9 & 18.7 & 18 & NA & NA & Subsegmentectomy & $\begin{array}{l}\text { Hepatocellular } \\
\text { carcinoma-well }\end{array}$ & 0 & 0 & 0 & LF & $\begin{array}{l}\text { Total } \\
\text { tumor }\end{array}$ & $\begin{array}{l}\text { Total, } \\
\text { heterogeneously }\end{array}$ \\
\hline 3 & 71 & M & $\mathrm{HCC}$ & $56 / 7$ & $8 \times 8$ & 2 & 4.4 & 10.4 & NA & 3.7 & 37.3 & $\begin{array}{l}\text { Posterior } \\
\text { segmentectomy }\end{array}$ & $\begin{array}{l}\text { Hepatocellular } \\
\text { carcinoma—mod }\end{array}$ & 0 & 0 & 0 & $\mathrm{NL}$ & $\begin{array}{l}\text { Total } \\
\text { tumor }\end{array}$ & $\begin{array}{l}\text { Total, } \\
\text { heterogeneously }\end{array}$ \\
\hline 4 & 49 & M & $\mathrm{HCC}$ & S7 & $1.5 \times 1.4$ & 1 & 7.9 & 32.9 & 25 & NA & NA & Subsegmentectomy & $\begin{array}{l}\text { Hepatocellular } \\
\text { carcinoma—mod }\end{array}$ & 0 & 0 & 1 & LC & Total tumor & $\begin{array}{l}\text { Total, } \\
\text { heterogeneously }\end{array}$ \\
\hline 5 & 54 & M & $\mathrm{HCC}$ & $\mathrm{S} 7 / 8$ & $3 \times 3$ & 1 & 14.7 & 90.8 & 95 & 4.2 & 0.2 & Partial resection & $\begin{array}{l}\text { Hepatocellular } \\
\text { carcinoma—mod }\end{array}$ & 0 & 0 & 0 & LC & $\begin{array}{l}\text { Total } \\
\text { tumor }\end{array}$ & $\begin{array}{l}\text { Total, } \\
\text { heterogeneously }\end{array}$ \\
\hline 6 & 75 & M & $\mathrm{HCC}$ & S8 & $2 \times 2$ & 1 & 17.3 & 1951.2 & 19 & NA & NA & Partial resection & $\begin{array}{l}\text { Hepatocellular } \\
\text { carcinoma-mod }\end{array}$ & 0 & 0 & 0 & LF & $\begin{array}{l}\text { Total } \\
\text { tumor }\end{array}$ & $\begin{array}{l}\text { Total, } \\
\text { heterogeneously }\end{array}$ \\
\hline 7 & 80 & $\mathrm{~F}$ & $\mathrm{HCC}$ & S4 & $4.5 \times 4.5$ & 1 & 18.3 & NA & 6087 & NA & NA & Partial resection & $\begin{array}{l}\text { Hepatocellular } \\
\text { carcinoma_por }\end{array}$ & 1 & 1 & 1 & $\mathrm{CH}$ & $\begin{array}{l}\text { Total } \\
\text { tumor }\end{array}$ & $\begin{array}{l}\text { Partial, } \\
\text { heterogeneously }\end{array}$ \\
\hline 8 & 78 & M & $\mathrm{HCC}$ & $\mathrm{S} 2 / 3$ & $11 \times 8$ & 1 & 37.3 & 56934 & 363000 & 1.9 & 7.1 & $\begin{array}{l}\text { Lateral } \\
\text { segmentectomy }\end{array}$ & $\begin{array}{l}\text { Hepatocellular } \\
\text { carcinoma_por }\end{array}$ & 1 & 0 & 1 & LF & $\begin{array}{l}\text { Total } \\
\text { tumor }\end{array}$ & $\begin{array}{l}\text { Partial, } \\
\text { heterogeneously }\end{array}$ \\
\hline 9 & 65 & M & $\mathrm{HCC}$ & S7 & $1.5 \times 1.5$ & 1 & 11.7 & 2.7 & 42 & 4.5 & NA & Partial resection & $\begin{array}{l}\text { Hepatocellular } \\
\text { carcinoma_por }\end{array}$ & 0 & 0 & 0 & LF & $\begin{array}{l}\text { Total } \\
\text { tumor }\end{array}$ & Rim \\
\hline 10 & 74 & M & $\mathrm{HCC}$ & S5 & $6 \times 6$ & 1 & 8.2 & 6.4 & 83 & 2.1 & 3.9 & Subsegmentectomy & $\begin{array}{l}\text { Hepatocellular } \\
\text { carcinoma—por }\end{array}$ & 0 & 0 & 1 & LC & $\begin{array}{l}\text { Total } \\
\text { tumor }\end{array}$ & $\begin{array}{l}\text { Partial, } \\
\text { heterogeneously }\end{array}$ \\
\hline 11 & 61 & M & $\mathrm{HCC}$ & S8 & $1.4 \times 1.4$ & 1 & 9.9 & 45.5 & 23 & NA & NA & Subsegmentectomy & $\begin{array}{l}\text { Hepatocellular } \\
\text { carcinoma-por }\end{array}$ & 0 & 0 & 1 & LC & $\begin{array}{l}\text { Total } \\
\text { tumor }\end{array}$ & $\begin{array}{l}\text { Partial, } \\
\text { heterogeneously }\end{array}$ \\
\hline 12 & 32 & $\mathrm{~F}$ & $\mathrm{HCC}$ & $\mathrm{S} 5 / 6 / 7 / 8$ & $15 \times 12$ & 1 & 7.0 & 1006.6 & 108 & 2.7 & 541.4 & Right lobectomy & $\begin{array}{l}\text { Hepatocellular } \\
\text { carcinoma-unknown }\end{array}$ & 0 & 0 & 0 & $\mathrm{NL}$ & $\begin{array}{l}\text { Total } \\
\text { tumor }\end{array}$ & Rim \\
\hline 13 & 66 & M & $\begin{array}{l}\text { Metastasis } \\
\text { of CRC }\end{array}$ & S6 & $2.5 \times 2.5$ & 1 & 16.1 & NA & NA & 2.7 & 6.3 & Subsegmentectomy & Adenocarcinoma-mod & NA & NA & NA & $\mathrm{NL}$ & $\begin{array}{l}\text { Total } \\
\text { tumor }\end{array}$ & Rim \\
\hline 14 & 70 & M & $\begin{array}{l}\text { Metastasis } \\
\text { of CRC }\end{array}$ & S6 & $2.5 \times 2.5$ & 1 & 11.5 & NA & NA & 3.1 & 2.2 & Partial resection & Adenocarcinoma-mod & NA & NA & NA & $\mathrm{NL}$ & Rim & Rim \\
\hline 15 & 72 & M & $\begin{array}{l}\text { Metastasis } \\
\text { of CRC }\end{array}$ & $\mathrm{S} 5 / 8$ & $4 \times 4$ & 1 & 9.7 & 4.1 & 17 & 6.6 & 8.9 & Partial resection & Adenocarcinoma-mod & NA & NA & NA & $\mathrm{NL}$ & Rim & Rim \\
\hline 16 & 58 & M & $\begin{array}{l}\text { Metastasis } \\
\text { of CRC }\end{array}$ & S6 & $0.8 \times 0.8$ & 1 & 16.0 & NA & NA & 2.4 & 44 & $\begin{array}{l}\text { Posterior } \\
\text { segmentectomy }\end{array}$ & Adenocarcinoma-mod & NA & NA & NA & $\mathrm{NL}$ & $\begin{array}{l}\text { Total } \\
\text { tumor }\end{array}$ & Rim \\
\hline 17 & 45 & M & $\begin{array}{l}\text { Metastasis } \\
\text { of CRC }\end{array}$ & S3 & $2.3 \times 1.6$ & 1 & 16.3 & NA & NA & 1.5 & 7 & $\begin{array}{l}\text { Lateral } \\
\text { segmentectomy }\end{array}$ & Adenocarcinoma-mod & NA & NA & NA & $\mathrm{NL}$ & $\begin{array}{l}\text { Total } \\
\text { tumor }\end{array}$ & Rim \\
\hline 18 & 74 & M & $\begin{array}{l}\text { Metastasis } \\
\text { of CRC }\end{array}$ & S6 & $1.5 \times 1.5$ & 1 & 5.0 & 3.9 & NA & 2.6 & 2.2 & Partial resection & Adenocarcinoma-mod & NA & NA & NA & $\mathrm{NL}$ & Rim & Rim \\
\hline 19 & 66 & M & $\begin{array}{l}\text { Metastasis } \\
\text { of CRC }\end{array}$ & S3, S4, S8 & $\begin{array}{l}\text { S3 } 4.8 \times 4.5 \\
\text { S4 } 4.6 \times 4.5 \\
\text { S8 } 1.7 \times 1.5\end{array}$ & 3 & 19.1 & NA & NA & 7 & 886.6 & $\begin{array}{l}\text { Left lobectomy, } \\
\text { partial resection }\end{array}$ & Adenocarcinoma-muc & NA & NA & NA & $\mathrm{NL}$ & $\begin{array}{l}\text { Total } \\
\text { tumor }\end{array}$ & Rim \\
\hline
\end{tabular}



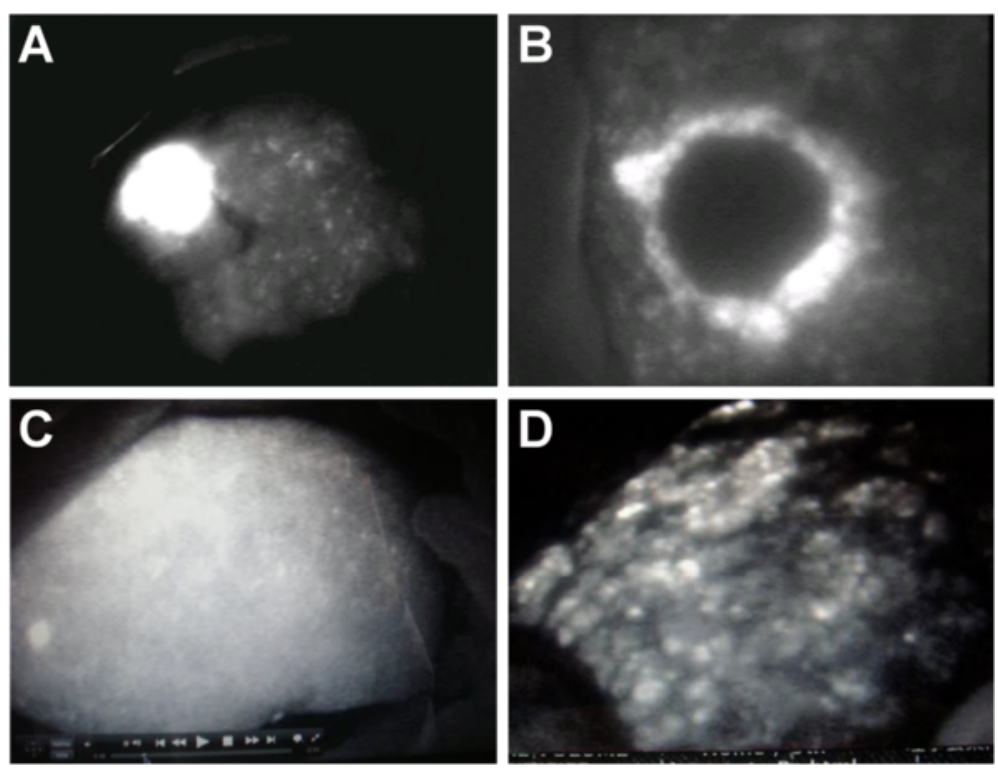

Fig. 1 Intraoperative ICG fluorescence imaging (IFI). a Total tumor type (case 6). b Rim type (case 14). c Normal livers (non-cancerous part) had uniform fluorescence after intraoperative ICG injection (case 3). $\mathbf{d}$ Cirrhotic livers (non-cancerous part) had heterogeneous fluorescence, and the regenerated nodule was strongly fluorescent (case 5)

was observed. In hepatocellular carcinoma, the IFI was heterogeneous and exhibited various patterns. In metastatic carcinoma, we observed that non-tumor cells in the marginal region showed fluorescence and tumor cells in the central region did not fluoresce.

ICG is generally used as a liver function assay [14]. Moreover, ICG, which is approved by the Food and Drug Administration, is safe and comparatively economical.
ICG combines with serum proteins in vivo and fluoresces under excitation at $760-820 \mathrm{~nm}[1]$.

In animal experiments, ICG that was injected into the peripheral vein accumulated in the liver [15] demonstrating that ICG has a high affinity for the liver.

Within the liver surgery field, ICG fluorescence imaging applications have been reported for the detection of HCC or metastases derived from CRC $[10,11,13]$

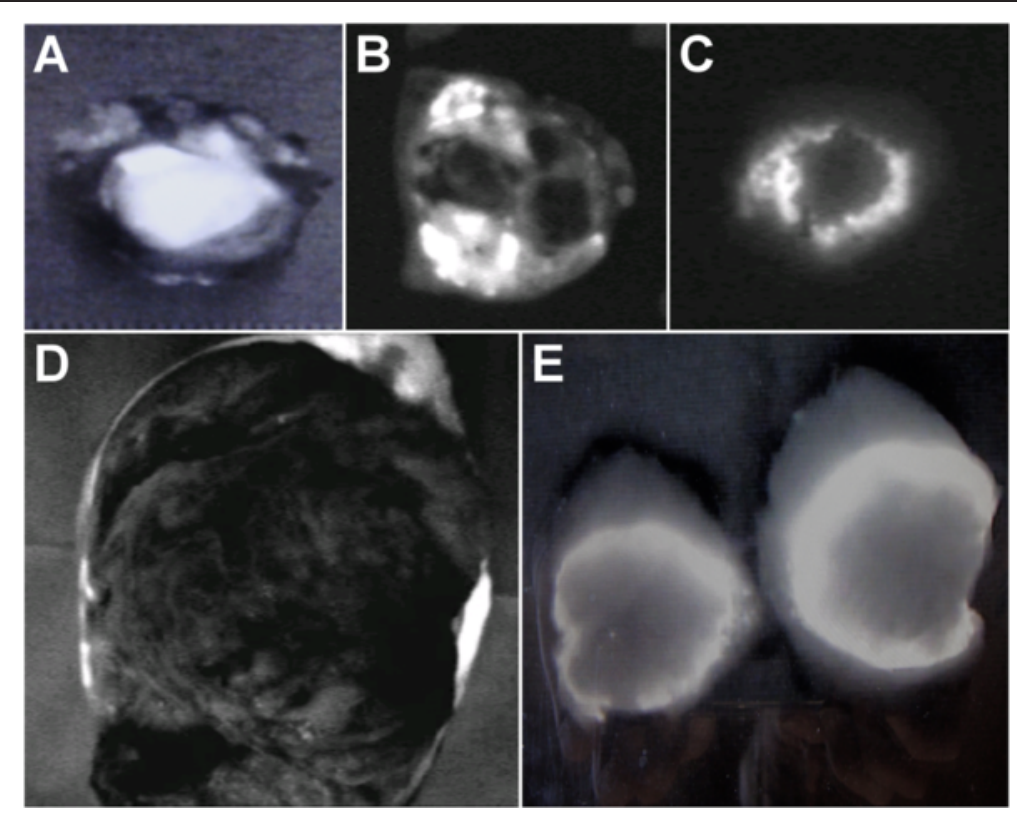

Fig. 2 Postoperative observation of liver specimen sections. a Total tumor type (case 5). b Partial tumor type (case 10). c Rim type (case 9). d Rim type (case 12). e Rim type (case 14) 

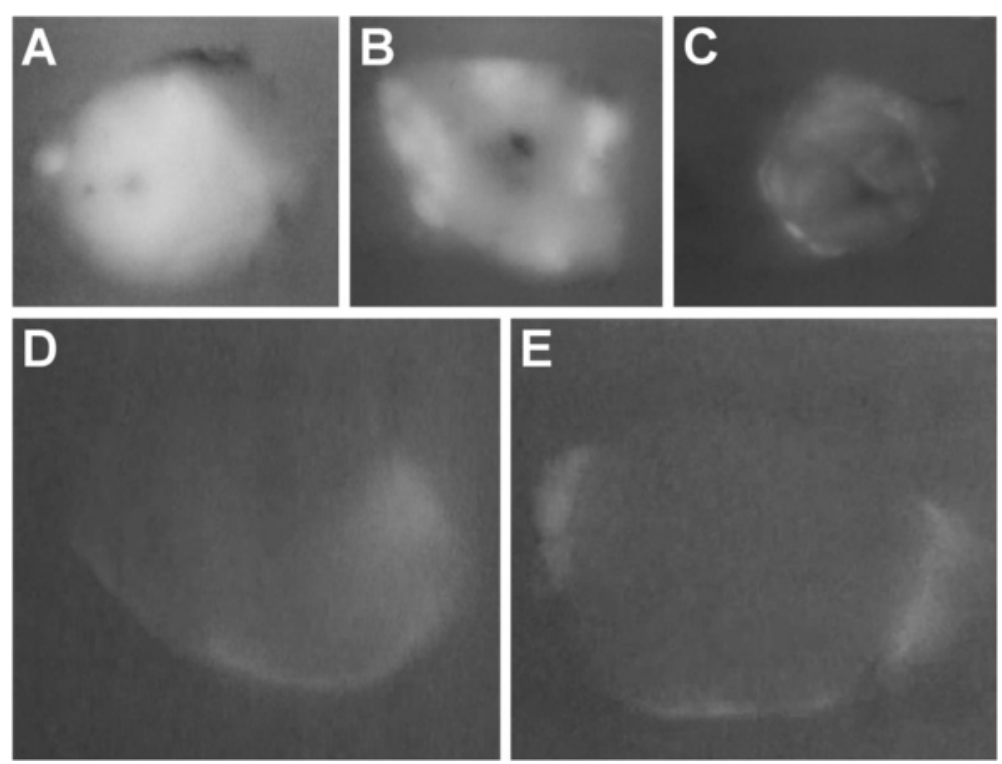

Fig. 3 ICG fluorescence imaging (IFI) of paraffin-embedded tissue samples. ICG fluorescence was present in paraffin-embedded tissue samples. a Total tumor type (case 5). b Partial tumor type (case 10). c Rim type (case 9). d Rim type (case 12). e Rim type (case 14)

and pancreatic cancer [12], tattooing of the liver segment $[7,8]$, detection of biliary leakage [16, 17], and evaluation of hepatic congested areas [18] and vascular flow [19] after liver transplantation via contrast of the biliary tract. OATP1B3 and $\mathrm{Na}+$ taurocholate cotransporting polypeptide (NTCP) have been demonstrated to transport ICG [20]. Eisai rats that lack functional MRP2 revealed that biliary ICG excretion is mediated by MRP2 [21].

Ishizawa et al. reported that well- or moderately differentiated HCC mostly displayed uniform or partial type fluorescence, poorly differentiated HCC mostly displayed rim type fluorescence, and metastatic tumors mostly displayed rim type fluorescence [10] in part because the degree of NTCP and OATP8 expression varied according to tumor differentiation [22]. Moreover, it was reported that there was a high false positive tumor detection rate in cirrhotic livers by using ICG fluorescence imaging [23]. In this study, these transporters were not evaluated, but the ICG fluorescence observations may be related to these transporters.

In this study, most tumors, particularly HCC tumors, appeared to be total tumor type from superficial observation. However, some cases had discrepancies between superficial observations and sectional observations.

All cases where the superficial observations were consistent with the sectional observations, except for the total tumor type, were cases where the tumor was exposed on the hepatic surface.

Although we observed that many IFI had total type fluorescence from the surface view, some tumor sections had partial or rim IFI. We believe that the IFI discrepancy between the surface and sections may be present in cases where the tumor is located far from the surface, resulting in unclear total IFI.

We observed consistent results between sections and paraffin-embedded tissues in most cases, including all metastatic tumor cases. However, the results were not consistent in three HCC cases. All these cases had poorly differentiated HCC. Poorly differentiated HCC cases had more variation in IFI results, i.e., the partial type or rim type, in comparison with well- and moderately differentiated HCC.

This result was consistent in sections and paraffinembedded tissues. We believe that the cause of the discrepancy between sections and paraffin-embedded tissues is IFI tumor heterogeneity.

This would suggest that IFI tumor heterogeneity increases as tumor differentiation fall. We suggest that ICG is excreted more slowly in less differentiated cancer cells. ICG uptake and excretion differ depending on the cancer cells, and we are able to perform this "heterogeneity" using a fluorescence microscope.

Ishizawa et al. reported that HCC of the total or partial tumor type exhibited fluorescence within the cytoplasm and pseudoglands under ICG fluorescence imaging. Additionally, $\mathrm{HCC}$ or metastatic cancer with the rim type had ICG fluorescence in non-cancer cells surrounding cancer cells [22]. They suggested that the cause was the following: while ICG portal uptake ability was preserved, biliary excretion ability was reduced in differentiated HCC [22]. The biliary excretion ability of 
Table 2 Paraffin block and microscopic observations of IFI

\begin{tabular}{|c|c|c|c|c|c|c|c|c|c|c|}
\hline Case & Age & Sex & Diagnosis & Location & Size $(\mathrm{cm})$ & Number & Non-cancerous live & IRI of paraffin block & IRI of microscopy & Time after operation \\
\hline 1 & 66 & $F$ & $\mathrm{HCC}$ & S6 & $3 \times 3$ & 1 & LC & Total, heterogeneously & Cytosol of cancer cell & 3 years, 8 months \\
\hline 2 & 79 & $\mathrm{~F}$ & $\mathrm{HCC}$ & 58 & $2 \times 2$ & 1 & LF & Total, heterogeneously & Cytosol of cancer cell & 2 years, 11 months \\
\hline 3 & 71 & M & $\mathrm{HCC}$ & S6/7 & $8 \times 8$ & 2 & $\mathrm{NL}$ & Total, heterogeneously & Cytosol of cancer cell & 3 years, 4 months \\
\hline 4 & 49 & M & $\mathrm{HCC}$ & S7 & $1.5 \times 1.4$ & 1 & LC & Total, heterogeneously & Cytosol of cancer cell & 3 years, 2 months \\
\hline 5 & 54 & M & $\mathrm{HCC}$ & $\mathrm{S} 7 / 8$ & $3 \times 3$ & 1 & LC & Total, heterogeneously & Cytosol of cancer cell & 2 years, 9 months \\
\hline 6 & 75 & M & $\mathrm{HCC}$ & S8 & $2 \times 2$ & 1 & LF & Total, heterogeneously & Cytosol of cancer cell & 1 year, 10 months \\
\hline 7 & 80 & $\mathrm{~F}$ & $\mathrm{HCC}$ & S4 & $4.5 \times 4.5$ & 1 & $\mathrm{CH}$ & Rim & $\begin{array}{l}\text { Nuclei of cancer cell and } \\
\text { cytosol of non-cancer cell }\end{array}$ & 1 year, 2 months \\
\hline 8 & 78 & M & $\mathrm{HCC}$ & $\mathrm{S} 2 / 3$ & $11 \times 8$ & 1 & LF & Rim & $\begin{array}{l}\text { Nuclei of cancer cell and } \\
\text { cytosol of non-cancer cell }\end{array}$ & 3 years, 4 months \\
\hline 9 & 65 & M & $\mathrm{HCC}$ & S7 & $1.5 \times 1.5$ & 1 & LF & Rim & $\begin{array}{l}\text { Nuclei of cancer cell and } \\
\text { cytosol of non-cancer cell }\end{array}$ & 3 months \\
\hline 10 & 74 & M & $\mathrm{HCC}$ & S5 & $6 \times 6$ & 1 & LC & Partial, heterogeneously & Cytosol of cancer cell & 2 years, 4 months \\
\hline 11 & 61 & M & $\mathrm{HCC}$ & S8 & $1.4 \times 1.4$ & 1 & LC & $\operatorname{Rim}$ & $\begin{array}{l}\text { Nuclei of cancer cell and } \\
\text { cytosol of non-cancer cell }\end{array}$ & 3 years, 7 months \\
\hline 12 & 32 & $\mathrm{~F}$ & $\mathrm{HCC}$ & $\mathrm{S} 5 / 6 / 7 / 8$ & $15 \times 12$ & 1 & $\mathrm{NL}$ & Rim & $\begin{array}{l}\text { Nuclei of cancer cell and } \\
\text { cytosol of non-cancer cell }\end{array}$ & 9 months \\
\hline 13 & 66 & M & Metastasis of CRC & S6 & $2.5 \times 2.5$ & 1 & $\mathrm{NL}$ & $\operatorname{Rim}$ & Cytosol of cancer cell & 3 years, 2 months \\
\hline 14 & 70 & M & Metastasis of CRC & S6 & $2.5 \times 2.5$ & 1 & $\mathrm{NL}$ & Rim & Cytosol of cancer cell & 2 years, 4 months \\
\hline 15 & 72 & M & Metastasis of CRC & $\mathrm{S} 5 / 8$ & $4 \times 4$ & 1 & $\mathrm{NL}$ & $\operatorname{Rim}$ & Cytosol of cancer cell & 1 year, 8 months \\
\hline 16 & 58 & M & Metastasis of CRC & S6 & $0.8 \times 0.8$ & 1 & $\mathrm{NL}$ & Rim & Cytosol of cancer cell & 2 years, 2 months \\
\hline 17 & 45 & M & Metastasis of CRC & S3 & $2.3 \times 1.6$ & 1 & $\mathrm{NL}$ & Rim & Cytosol of cancer cell & 1 year, 4 months \\
\hline 18 & 74 & M & Metastasis of CRC & S6 & $1.5 \times 1.5$ & 1 & $\mathrm{NL}$ & $\operatorname{Rim}$ & Cytosol of cancer cell & 1 year, 3 months \\
\hline 19 & 66 & M & Metastasis of CRC & $\mathrm{S3}, \mathrm{S} 4, \mathrm{~S} 8$ & $\begin{array}{l}\text { S3 } 4.8 \times 4.5, \text { S4 } 4.6 \times \\
4.5, \text { S8 } 1.7 \times 1.5\end{array}$ & 3 & $\mathrm{NL}$ & Rim & Cytosol of cancer cell & 4 months \\
\hline
\end{tabular}




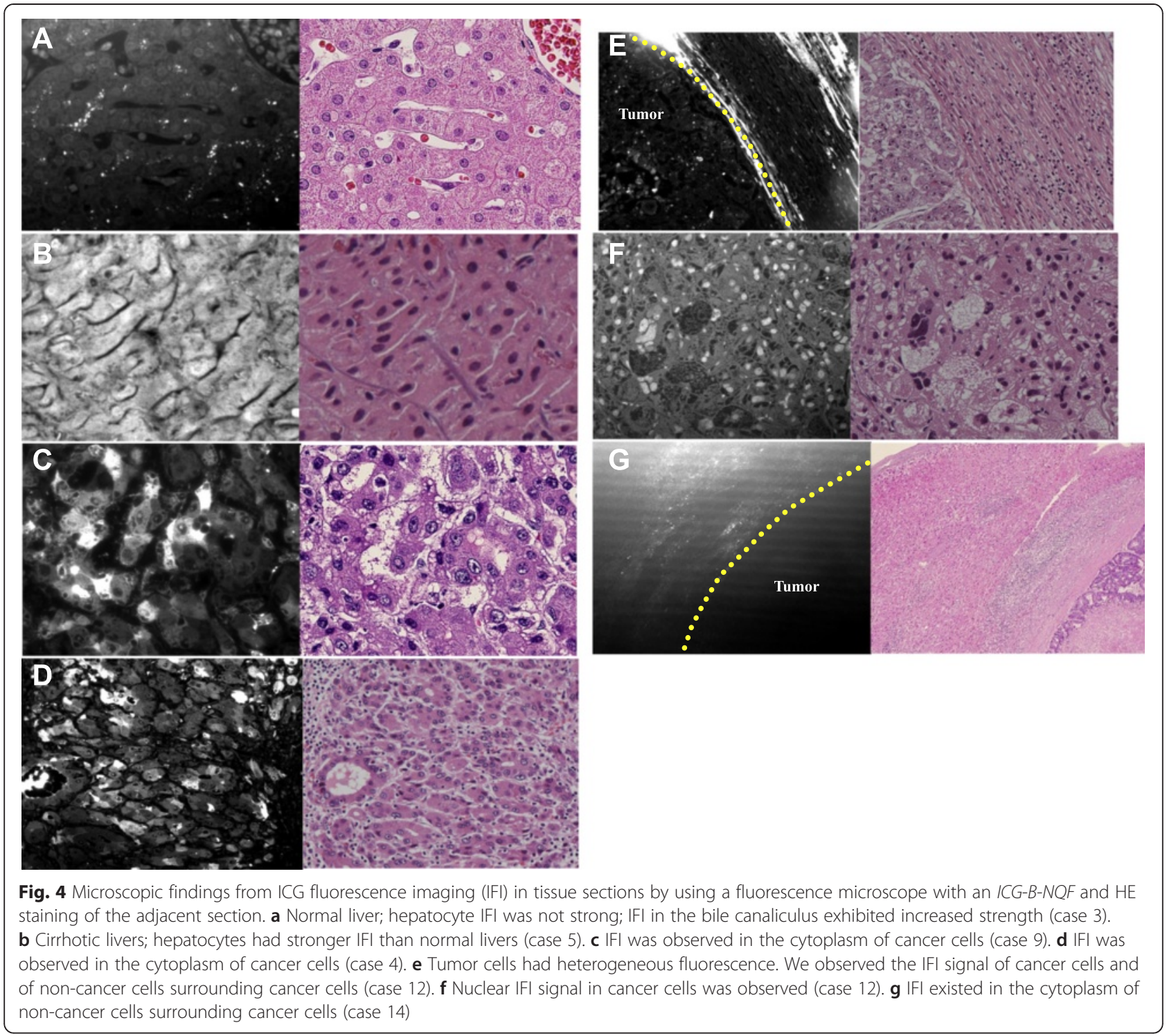

normal hepatocytes declined due to compression from the tumor in poorly differentiated HCC or metastatic cancer.

Consistent with these reports, in the present study, it was observed that the total or partial tumor type of HCC exhibited cytoplasmic fluorescence signal under ICG fluorescence microscopy, and metastatic cancers with the rim type exhibited ICG fluorescence in noncancer cells surrounding the cancer cells. In some cases that exhibited rim IFI in poorly differentiated HCC or $\mathrm{HCC}$ of unknown differentiation status, there was nuclear IFI signal in cancer cells and cytoplasmic IFI signal in non-cancer cells surrounding the cancer cells.

Cancer cells may not fluoresce in metastatic liver cancer cases because cancer cells do not have the characteristics of hepatocytes. Macroscopic observations between metastatic liver cancer and $\mathrm{HCC}$ with the rim type were the same; however, microscopic observations between metastatic liver cancer and $\mathrm{HCC}$ with the rim type were somewhat disparate. While cancer cells did not exhibit IFI signal in metastatic liver cancers, the cancer cells exhibited IFI signal in different regions in poorly differentiated HCC or HCC of unknown differentiation status compared with other types. The exact cause of this phenomenon is elusive but may be related to the tumor characteristics derived from differentiation. Further investigation is necessary to clarify these observations.

In non-cancerous liver tissue, hepatocytes in cirrhotic livers had stronger IFI values than non-cirrhotic livers. However, there were stronger IFI values in the bile canaliculus in non-cirrhotic livers than cirrhotic livers. This result may be due to the early washout of ICG resulting from the preserved ICG-excretion ability of hepatocytes. 
After ICG injection, we observed immediate emission and early washout in the normal liver. Conversely, we observed late emission and late washout in cirrhotic livers as an aggravation of cirrhosis. Therefore, the regenerated nodule had an emission as strong as the tumor. In certain instances, there may not be a differentiation between the regenerated nodule and the tumor.

In this study, we successfully performed IFI at the cellular level using fluorescence microscopy with an ICG$B-N Q F$. This type of research is rare and is a useful method for progressing ICG fluorescence method research. However, the limitation of this study is the following. The period from surgery to observation was different about the paraffin blocks and microscopic sections because we retrospectively observed these samples. Then, we could not compare fluorescence intensity between three imaging techniques because the devices and condition between three imaging techniques were different.

In this study, we were able to observe fluorescence in a paraffin-embedded tumor tissue sample that was obtained more than 3 years earlier. Therefore, we can retrospectively evaluate tumor fluorescence. For example, we could retrospectively detect micro lesions in histopathological specimens using the ICG fluorescence method. It has been suggested that ICG, which is bound to intracellular proteins, is preserved in paraffin-embedded tissue. However, the precise mechanism of the ICG fluorescence retention is elusive. We did not investigate the optimal conditions for paraffin-embedded tissue to preserve fluorescence intensity. Further study is necessary to define the optimal conditions for preserving the fluorescence signal. However, we believe that discovering that ICG fluorescence in paraffin-embedded tissue samples can be retrospectively observed is very important.

\section{Conclusions}

We confirmed that the variations of ICG fluorescence imaging patterns reflect different tumor characteristics in not only macroscopic imaging as previous reports $[10,22]$ but also microscopic imaging. Moreover, the ICG fluorescence method is also useful for postoperative pathological detection of micro lesions in histopathological specimens. ICG fluorescence in paraffin-embedded tissue samples and formalin-fixed specimens is preserved in the long term. However, further investigations are needed to clarify the reasons and optimal conditions for sample preservation.

\footnotetext{
Abbreviations

CCD: charge-coupled device; $\mathrm{CH}$ : chronic hepatitis; $\mathrm{CRC}$ : colorectal cancer; HCC: hepatocellular carcinoma; ICG: indocyanine green; IFI: ICG fluorescence imaging; LC: liver cirrhosis; LF: liver fibrosis; MRP2: multidrug resistance associated protein 2; NL: normal liver; NTCP: Na+ taurocholate cotransporting polypeptide; OATP: organic anion transporting polypeptide; PDE: photo dynamic emission.
}

\section{Competing interests}

All of the authors declare that they have no competing interests.

\section{Authors' contributions}

SS carried out the analysis of data and observation of the liver and wrote the manuscript. SO provided the fluorescence microscope system. KO and MK gave comments and revised the manuscript. All authors read and approved the final manuscript.

\section{Acknowledgements}

The authors would like to thank the staff of the Department of Surgery of the Japan Labor Health and Welfare, Kushiro Rosai Hospital, for their kind cooperation.

\section{Author details}

${ }^{1}$ Department of Surgery, Japan Labor Health and Welfare Organization, Kushiro Rosai Hospital, 13-12, Nakazono-cho, Kushiro, Hokkaido 085-8533, Japan. ${ }^{2}$ Department of Oral and Maxillofacial Surgery, Japan Labor Health and Welfare Organization, Kushiro Rosai Hospital, 13-12, Nakazono-cho, Kushiro, Hokkaido 085-8533, Japan. ${ }^{3}$ Department of Surgery, Seiwa Memorial Hospital, 1-5-1-1, Kotoni, Nishi-ku, Sapporo, Hokkaido 063-0811, Japan.

Received: 22 January 2015 Accepted: 28 May 2015

Published online: 10 June 2015

\section{References}

1. Tanaka E, Choi HS, Fujii H, Bawendi MG, Frangioni JV. Image-guided oncologic surgery using invisible light: completed pre-clinical development for sentinel lymph node mapping. Ann Surg Oncol. 2006;13:1671-81.

2. Kitai T, Inamoto T, Miwa M, Shikayama T. Fluorescence navigation with indocyanine green for detecting sentinel lymph nodes in breast cancer patients. Breast Cancer. 2005;12:211-5.

3. Kusano M, Tajima Y, Yamazaki K, Kato M, Watanabe M, Miwa M. Sentinel node mapping guided by indocyanine green fluorescence imaging: a new method for sentinel node navigation surgery in gastrointestinal cancer. Dig Surg. 2008;25:103-8.

4. Tajima Y, Yamazaki K, Masuda Y, Kato M, Yasuda D, Aoki T, et al. Sentinel node mapping guided by indocyanine green fluorescence imaging in gastric cancer. Ann Surg. 2009;249:58-62.

5. Parungo CP, Ohnishi S, Kimu SW, Kim S, Laurence RG, Soltesz EG, et al. Intraoperative identification of esophageal sentinel lymph nodes with near-infrared fluorescence imaging. J Thorac Cardiovasc Surg. 2005;129:844-50.

6. Rubens FD, Ruel M, Fremes SE. A new and simplified method for coronary and graft imaging during CABG. Heart Surg Forum. 2002;5:141-4.

7. Aoki T, Yasuda D, Shimizu Y, Odaira M, Niiya T, Kusano T, et al. Image-guided liver mapping using fluorescence navigation system with indocyanine green for anatomical hepatic resection. World J Surg. 2008;32:1763-7.

8. Uchiyama K, Ueno M, Ozawa S, Kiriyama S, Shigekawa Y, Hirono S, et al. Combined intraoperative use of contrast-enhanced ultrasonography imaging using a sonazoid and fluorescence navigation system with indocyanine green during anatomical hepatectomy. Langenbecks Arch Surg. 2011;396:1101-7.

9. Ishizawa T, Tamura S, Masuda K, Aoki T, Hasegawa K, Imamura H, et al. Intraoperative fluorescent cholangiography using indocyanine green: a biliary road map for safe surgery. J Am Coll Surg. 2009;208:e1-4.

10. Ishizawa T, Fukushima N, Shibahara J, Masuda K, Tamura S, Aoki T, et al. Real-time identification of liver cancers by using indocyanine green fluorescent imaging. Cancer. 2009;115:2491-504.

11. Morita Y, Sakaguchi T, Unno N, Shibasaki Y, Suzuki A, Fukumoto K, et al. Detection of hepatocellular carcinomas with near-infrared fluorescence imaging using indocyanine green: its usefulness and limitation. Int J Clin Oncol. 2013;18:232-41.

12. Yokoyama N, Otani T, Hashidate H, Maeda C, Katada T, Sudo N, et al. Real-time detection of hepatic micrometastases from pancreatic cancer by intraoperative fluorescence imaging. Cancer. 2012;118:2813-9.

13. van der Vorst JR, Schaafsma BE, Hutteman M, Verbeek FP, Liefers GJ, Hartgrink $\mathrm{HH}$, et al. Near-infrared fluorescence-guided resection of colorectal liver metastases. Cancer. 2013;119:3411-8.

14. Kanematsu T, Furui J, Yanaga K, Okudaira S, Shimada M, Shirabe K. A 16-year experience in performing hepatic resection in 303 patients with hepatocellular carcinoma. Surgery. 2002;131:s153-8.

15. Yaseen MA, Yu J, Wong MS, Anvari B. In-vivo fluorescence imaging of mammalian organs using charge-assembled mesocapsule constructs containing indocyanine green. Opt Express. 2008;16:20577-87. 
16. Sakaguchi T, Suzuki A, Unno N, Morita Y, Oishi K, Fukumoto K, et al. Bile leak test by indocyanine green fluorescence images after hepatectomy. Am J Surg. 2010;200:e19-23.

17. Kaibori M, Ishizaki M, Matsui K, Kwon AH. Intraoperative indocyanine green fluorescent imaging for prevention of bile leakage after hepatic resection. Surgery. 2011;150:91-8.

18. Kawaguchi Y, Sugawara Y, Ishizawa T, Satou S, Kaneko J, Tamura S, et al. Identification of veno-occlusive regions in a right liver graft after reconstruction of vein segments 5 and 8: application of indocyanine green fluorescence imaging. Liver Transpl. 2013;19:778-9.

19. Kubota K, Kita J, Shimoda M, Rokkaku K, Kato M, Iso Y. Intraoperative assessment of reconstructed vessels in living-donor liver transplantation, using a novel fluorescence imaging technique. J Hepatobiliary Pancreat Surg. 2006;13:100-4.

20. Stieger B, Heger M, Graaf W, Paumgartner G, Gulik T. The emerging role of transport systems in liver function tests. Eur J Pharmacol. 2012;675:1-5.

21. Sathirakul K, Suzuki H, Yasuda K, Hanano M, Tagaya O, Horie T, et al. Kinetic analysis of hepatobiliary transport of organic anions in Eisai hyperbilirubinemic mutant rats. J Pharmacol Exp Ther. 1993;265:1301-12.

22. Ishizawa T, Masuda K, Urano Y, Kawaguchi Y, Satou S, Kaneko J, et al. Mechanistic background and clinical applications of indocyanine green fluorescence imaging of hepatocellular carcinoma. Ann Surg Oncol. 2014;21:440-8.

23. Tanaka T, Takatsuki M, Hidaka M, Hara T, Muraoka I, Soyama A, et al. Is a fluorescence navigation system with indocyanine green effective enough to detect liver malignancies? J Hepatobiliary Pancreat Surg. 2014;21:199-204.

\section{Submit your next manuscript to BioMed Central and take full advantage of:}

- Convenient online submission

- Thorough peer review

- No space constraints or color figure charges

- Immediate publication on acceptance

- Inclusion in PubMed, CAS, Scopus and Google Scholar

- Research which is freely available for redistribution 